\title{
Prototipe Sistem Penerima Tamu dengan Fasilitas Komunikasi Alternatif Secara Nirkabel
}

\author{
Akuwan Saleh ${ }^{1}$, Haryadi Amran D ${ }^{2}$ \\ 1.2Jurusan Teknik Telekomunikasi, Politeknik Elektronika Negeri Surabaya \\ Institut Teknologi Sepuluh Nopember (ITS), Surabaya, Indonesia \\ Kampus ITS Keputih Sukolilo, Surabaya, 60111 \\ Telp. +62 (31) 5947280 Fax +62 (31) 5946114 \\ E-mail: \\ akuwan@eepis-its.edu
}

\begin{abstract}
Abstrak
Prototipe sistem penerima tamu yang telah dibuat dalam paper ini menggunakan mikrokontroler ATmega8535 dirancang dengan tujuan memberikan kemudahan bagi tamu dan penghuni rumah untuk melakukan komunikasi baik secara langsung maupun secara nirkabel melalui Handphone (HP). Prototipe ini telah diterapkan pada rumah yang memiliki kamar lebih dari satu. Komponen utama dari peralatan ini adalah bel, LCD, keypad, mikrokontroler ATmega8535, AT Command, PDU (Protokol Data Unit), HandPhone.

Pada minimum sistem peralatan ini tersedia menu berupa daftar nama dan kamar penghuni. Tamu memasukkan nama dan nomor kamar yang dituju maka bel pada kamar yang dituju berbunyi. Apabila penghuni berada dikamar dan menekan tombol jawaban, maka LCD pada sisi tamu keluar informasi "Mohon Tunggu Sebentar". Apabila penghuni tidak berada dikamar maka dalam beberapa menit LCD pada sisi tamu muncul informasi "Maaf Yang Dicari Tidak Ada, Mohon Tinggalkan Pesan Dengan Menulis Nama Dan Nomor Telepon". Selanjutnya pesan tersebut oleh mikrokontroler dikirimkan melalui HP server kepada HP penghuni. Hasil yang telah diperoleh dari sistem ini berupa informasi kepastian ada atau tidak adanya penghuni rumah, keberhasilan pengiriman identitas tamu (nama dan no. Telepon) melalui layanan SMS yang kemudian dilanjutkkan dengan komunikasi alternatif antara penghuni rumah dan tamu secara nirkabel menggunakan HP.
\end{abstract}

Kata kunci : Mikrokontroler, AT Command, PDU, HP, SMS.

\section{PENDAHULUAN}

Seiring dengan banyaknya aktivitas yang dilakukan oleh manusia untuk memenuhi kebutuhan hidupnya maka manusia dituntut untuk melakukan segala sesuatu dengan cepat, tepat dan efisien. Demikian pula dalam bidang komunikasi, manusia membutuhkan komunikasi untuk mendapatkan informasi yang lebih cepat.

Setiap orang yang akan bertamu, dan agar penghuni dapat mengetahui kedatangan tamu adalah dengan menekan bel atau mengetuk pintu. Namun jika tamu berkunjung di suatu gedung dengan penghuni yang relatif banyak, tentu tamu merasa kesulitan untuk memanggil penghuni yang dicarinya dan tamu kemungkinan menunggu lama untuk mendapatkan suatu jawaban yang pasti apakah yang dicari itu ada atau tidak ada. Untuk mengatasi semua masalah tersebut diatas, diperlukan sebuah sistem untuk mengetahui kedatangan tamu dan memstikan ada tidaknya penghuni didalam rumah serta tamu dapat berkomunikasi secara nirkabel menggunakan Handphone yang diawali koneksinya oleh piranti mikrokontroler.

\section{LANDASAN TEORI}

\subsection{AVR ATmega8535}

AVR merupakan seri mikrokontroller CMOS 8-bit buatan Atmel, berbasis arsitektur RISC (Reduced Instruction Set Computer). Hampir semua instruksi dieksekusi dalam satu siklus clock. AVR mempunyai 32 register general-purpose, timer/counter fleksibel dengan mode compare, interupt internal dan eksternal, serial UART, programmable Watchdog Timer, dan mode power saving. Beberapa diantaranya mempunyai ADC dan PWM internal. AVR juga mempunyai In-System Programmable Flash on-chip yang mengijinkan memori program untuk diprogram ulang dalam sistem menggunakan hubungan serial 
SPI. Chip AVR ATmega8535 adalah mikrokontroller CMOS 8-bit daya-rendah berbasis arsitektur RISC yang ditingkatkan. Kebanyakan instruksi dikerjakan pada satu siklus clock, ATmega8535 mempunyai throughput mendekati 1 MIPS per $\mathrm{MHz}$ membuat disainer sistem untuk mengoptimasi komsumsi daya versus kecepatan proses.

\subsection{Short Message Service Centre (SMSC)}

Short message service centre (SMSC) adalah kombinasi perangkat keras dan perangkat lunak yang bertanggung jawab memperkuat, menyimpan dan meneruskan pesan pendek antara SMS dan piranti bergerak. SMSC harus memiliki kehandalan, kapasitas pelanggan, dan throughput pesan yang tinggi. Selain itu, SMS juga harus dapat diskalakan dengan mudah untuk mengakomodasikan peningkatan permintaan SMS dalam jaringan yang ada. SMSC mentransfer pesan dalam format Point to point pada sistem yang melayani.

\subsection{Mekanisme Store dan Forward pada SMS}

SMS adalah data tipe asynchoronous message yang pengiriman datanya dilakukan dengan mekanisme protokol store and forward. Hal ini berarti bahwa pengirim dan penerima SMS tidak perlu berada dalam status berhubungan (connected/ online) satu sama lain ketika akan saling bertukar pesan SMS. Pengiriman pesan SMS secara store and forward berarti pengirim pesan SMS menuliskan pesan dan nomor telepon tujuan dan kemudian mengirimkannya (store) ke server SMS (SMS-Center) yang kemudian bertanggung jawab untuk mengirimkan pesan tersebut (forward) ke nomor telepon tujuan. Keuntungan mekanisme store and forward pada SMS adalah, penerima tidak perlu dalam status online ketika ada pengirim yang bermaksud mengirimkan pesan kepadanya, karena pesan akan dikirim oleh pengirim ke SMSC yang kemudian dapat menunggu untuk meneruskan pesan tersebut ke penerima ketika ia siap dan dalam status online di lain waktu. Ketika pesan SMS telah terkirim dan diterima oleh SMSC, pengirim akan menerima pesan singkat (konfirmasi) bahwa pesan telah terkirim (message sent). Hal-hal inilah yang menjadi kelebihan SMS dan populer sebagai layanan praktis dari sistem telekomunikasi bergerak.



Gambar 1. Mekanisme Store dan Forward

\subsection{AT Command}

Dibalik tampilan menu message pada ponsel sebenarnya adalah AT Command yang bertugas mengirim atau menerima data ke atau dari SMSCenter. AT Command tiap-tiap SMS device bisa berbeda-beda, tetapi pada dasarnya sama. Beberapa AT Command yang penting untuk SMS yaitu :

- AT+CMGS : untuk mengirim SMS

- AT+CMGL : untuk memeriksa SMS

- AT+CMGD : untuk menghapus SMS

AT Command untuk SMS, biasanya diikuti oleh data I/O yang diwakili oleh unit-unit PDU.

\subsection{PDU Sebagai Bahasa SMS dan Bagian - Bagiannya}

Data yang mengalir ke atau dari SMS-Center harus berbentuk PDU (Protocol Data Unit). PDU berisi bilangan-bilangan heksadesimal yang mencerminkan bahasa I/O. PDU terdiri atas beberapa Header. Header untuk kirim SMS ke SMS-Center berbeda dengan SMS yang diterima dari SMS-Center.

Maksud dari bilangan heksadesimal adalah bilangan yang terdiri atas $0,1,2,3,4,5,6,7,8,9, A, B, C, D, E, F$. PDU untuk mengirim SMS terdiri atas delapan header, sebagai berikut :

1. Nomor SMS-Center

2. Tipe SMS

3. Nomor Referensi SMS

4. Nomor Ponsel Penerima

5. Bentuk SMS

6. Skema Encoding Data I/O

7. Jangka Waktu Sebelum SMS Expired

8. Isi SMS

\subsection{Struktur Program Assembly}

Bentuk umum struktur program bahasa assembler yamg digunakan dalam pembuatan program dalam sistem ini menggunakan struktur sebagai berikut:

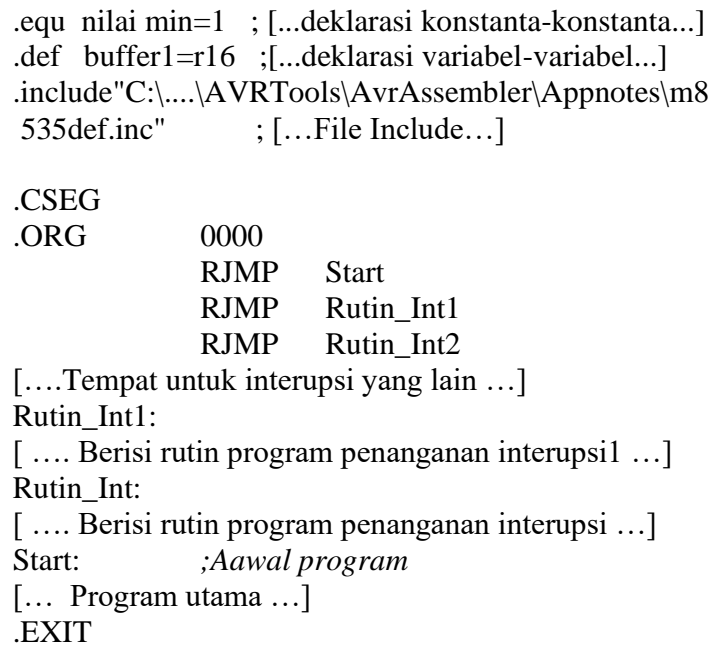




\section{PERANCANGAN SISTEM}

Perancangan sistem yang telah dibuat seperti diperlihatkan pada gambar 2. memanfaatkan perangkat keras dan perangkat lunak.

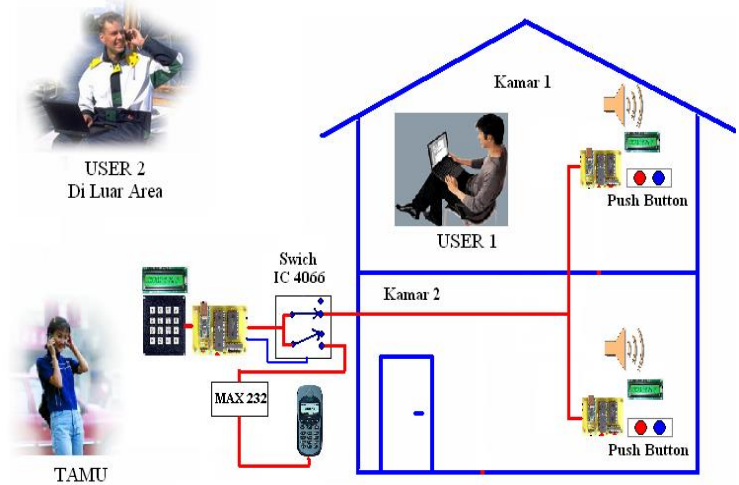

Gambar 2. Rancangan Sistem Penerima Tamu

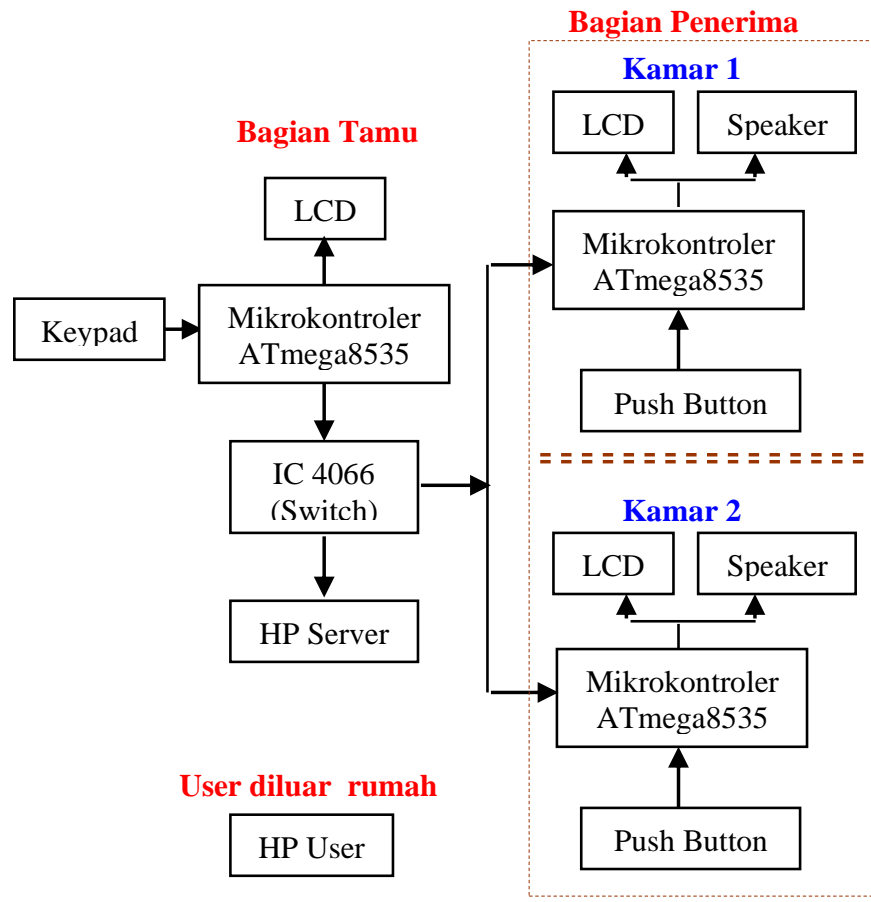

Gambar 3. Blok Diagram Sistem Penerima Tamu

Kinerja sitem penerima tamu yaitu jika pada tamu menekan keypad untuk memasukkan nomor ruang dan nama orang yang dituju, maka speaker pada ruang yang dituju berbunyi dan LCD pada ruang tersebut menampilkan nama penghuni yang dicari tamu. Apabila penghuni berada didalam kamar dan menekan push button warna biru, maka LCD pada sisi tamu ditampilkan tulisan "Mohon Tunggu Sebentar". Apabila penghuni tidak berada dikamar, secara otomatis dalam beberapa menit atau dengan menekan push button warna merah, maka LCD pada sisi tamu muncul tulisan "Maaf Yang Dicari Tidak Ada, Mohon Tinggalkan Pesan Dengan Menulis Nama Dan Nomor Telepon". Jika tamu menuliskan pesan tersebut melalui keypad oleh mikrokontroller akan diproses, sehingga nama dan nomor telepon dikirimkan melalui SMS HP server kepada HP user yang berada diluar rumah. Skema rangkaian sistem penerima tamu dengan fasilitas komunikasi alternatif secara nirkabel (HP) yang telah dibuat sesuai perancangan adalah sebagai berikut:

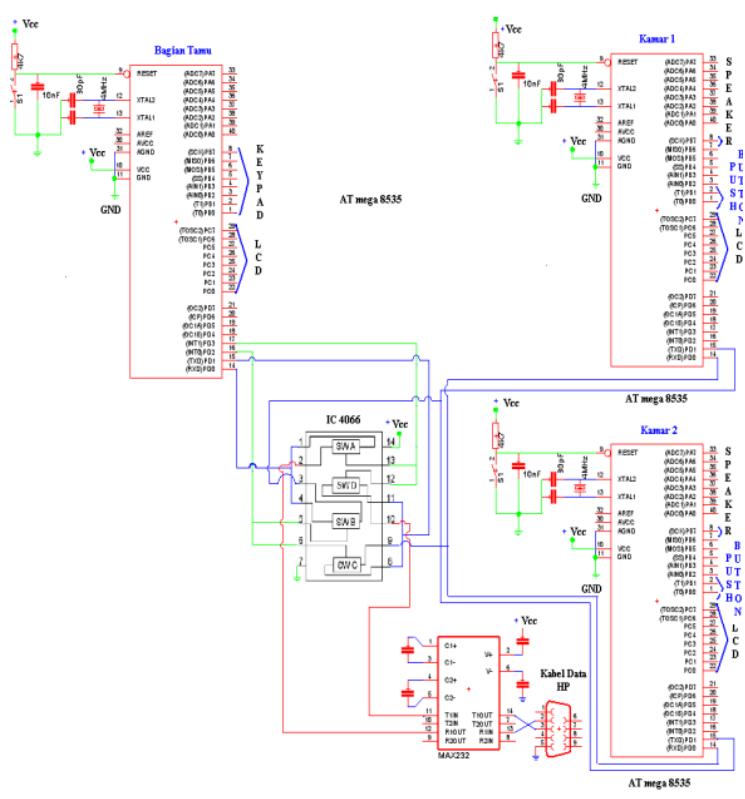

Gambar 4. Rangkaian Sistem Penerima Tamu

Pembuatan perangkat lunak yang telah dibuat dari sistem penerima tamu diperlhatkan pada gambar 5 .

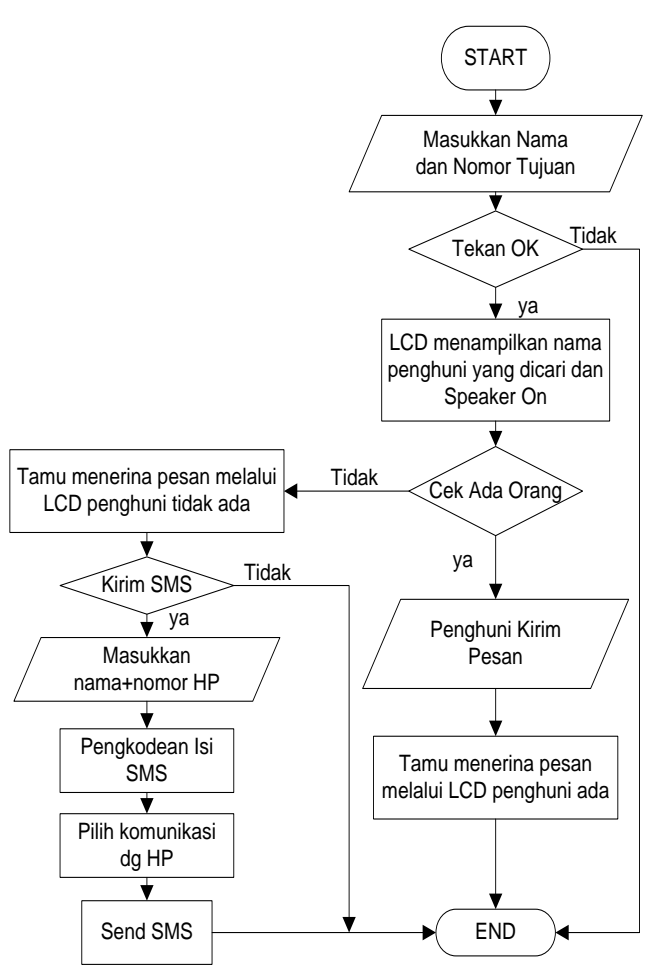

Gambar 5. Flowchart Sistem Penerima Tamu 


\section{PENGUJIAN DAN ANALISA}

4.1 Pengujian Komunikasi serial dengan RS232

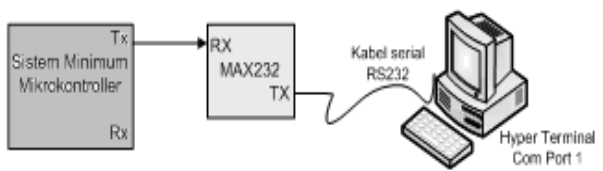

Gambar 6. Blok Diagram Pengujian komunikasi serial RS232

Hasil pengamatan program komunikasi serial RS232 pada Hyper Terminal dapat dilihat pada tabel 1, tabel 2 dan gambar 7.

Tabel 1. Hasil Pengujian Baudrate

\begin{tabular}{|c|c|c|}
\hline Baudrate & $\begin{array}{c}\text { Data } \\
\text { Terkirim }\end{array}$ & $\begin{array}{c}\text { Data Error / Tidak } \\
\text { Terkirim }\end{array}$ \\
\hline 1200 & & $\sqrt{ }$ \\
\hline 2400 & & $\sqrt{ }$ \\
\hline 4800 & & $\sqrt{ }$ \\
\hline 9600 & $\sqrt{ }$ \\
\hline 19200 & & $\sqrt{ }$ \\
\hline 38400 & & $\sqrt{ }$ \\
\hline 57600 & & $\sqrt{ }$ \\
\hline 115200 & & $\sqrt{ }$ \\
\hline 230400 & & \\
\hline 460800 & & $\sqrt{ }$ \\
\hline 921600 & & \\
\hline
\end{tabular}

\begin{tabular}{|c|}
\hline ijna - HyperTerminal \\
\hline File Edit View Call Transfer Help \\
\hline 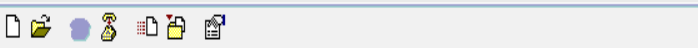 \\
\hline $\begin{array}{l}\text { Contoh Interupsi Serial Tekan A, B, C atau sembarang } \\
\text { indra coba hyperterminal }\end{array}$ \\
\hline
\end{tabular}

Gambar 7. Pengujian Komunikasi Serial pada Hyper Terminal

Tabel 2. Hasil Pengujian Komunikasi Serial

\begin{tabular}{|c|c|}
\hline Input & Output \\
\hline $\mathrm{A}$ & $\mathrm{A}$ \\
\hline $\mathrm{b}$ & $\mathrm{b}$ \\
\hline 1 & 1 \\
\hline
\end{tabular}

4.2 Pengujian Protokol Komunikasi Handphone Siemens M35

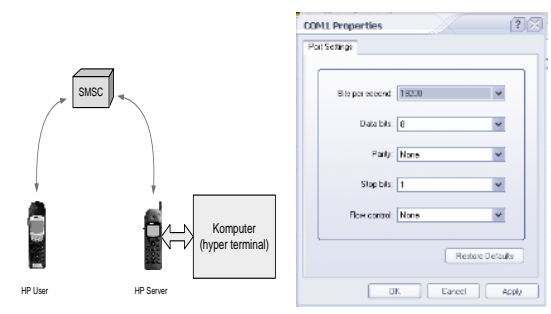

Gambar 8. Pengujian Protokol Komunikasi HP Siemens M35 dengan Hyper Terminal.

Pada Hyper Terminal diketikkan perintah AT Command. Pada pengujian sistem pengiriman SMS yang digunakan adalah $\mathrm{AT}+\mathrm{CMGS}=19$. Lalu dikirim format PDU seperti pada tabel dibawah kemudian diakhiri Ctrl Z.

Tabel 3. Pengujian Pengiriman SMS

\begin{tabular}{|c|c|}
\hline Format PDU yang dikirim & $\begin{array}{c}\text { Text diterima } \\
\text { HP User }\end{array}$ \\
\hline $\begin{array}{c}\text { 07912658050000F001000D91265 } \\
\text { 846458603F3000005E8329BFD06 }\end{array}$ & hello \\
\hline
\end{tabular}

\subsection{Pengujian Pengiriman SMS dengan Mikrokontroller}

Mikrokontroller yang terhubung dengan HP server pada bagian ini mengirimkan data nama dan nomor telepon dari keypad yang ditampilkan di LCD. Data tersebut diterima oleh MAX232, yang kemudian melalui kabel data merk HP yang digunakan ( Siemens M35 ) dikirimkan ke nomor SMS Center HP server kepada HP user yang tidak berada dikamar. Maksimal nama yang ditulis 6 karakter dan nomor HP 12 karakter. Pengujian sistem pengiriman SMS dengan mikrokontroler sebagai berikut:

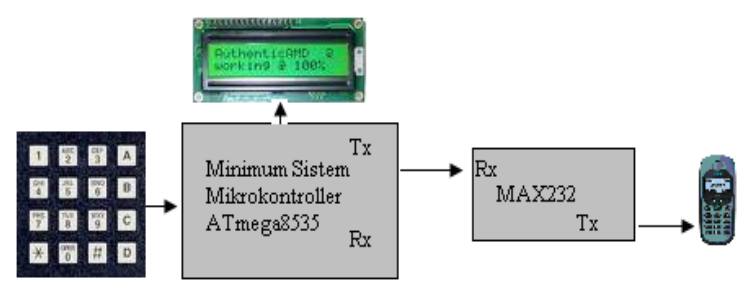

Gambar 9. Pengujian Pengiriman SMS dengan Mikrokontroller

Hasil pengujian sistem pengiriman SMS yang dilakukan oleh Mikrokontroller sebagai berikut:

Tabel 4. Hasil Pengujian Penerimaan SMS

\begin{tabular}{|c|c|}
\hline Isi SMS & $\begin{array}{c}\text { Hasil SMS } \\
\text { Penerima }\end{array}$ \\
\hline INDRA & INDRA \\
085646468303 & 085646468303 \\
\hline
\end{tabular}




\subsection{Pengujian Integrasi Sistem}

Pengujian integrasi sistem sesuai dengan blok diagram diperlihatkan pada gambar 10 .

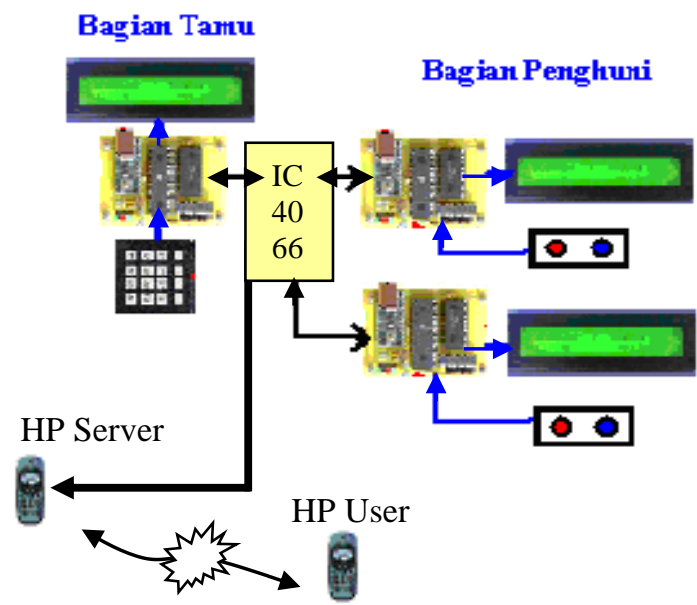

Gambar 10. Pengujian Integrasi Sistem

Daftar kamar dan penghuni :

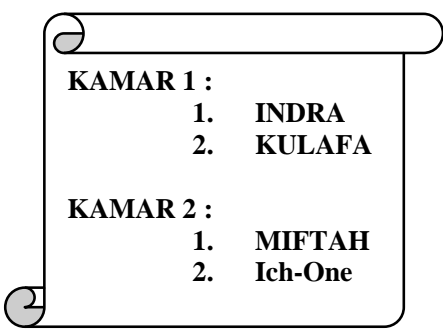

Tabel 5. Hasil Pengujian Kedatangan Tamu

\begin{tabular}{|c|c|c|c|c|c|}
\hline \multicolumn{2}{|c|}{ Keypad TAMU } & \multicolumn{2}{|c|}{ LCD PENGHUNI } & \multicolumn{2}{c|}{ BEL } \\
\hline $\begin{array}{c}\text { No. } \\
\text { Kmr }\end{array}$ & $\begin{array}{c}\text { No. } \\
\text { Nama }\end{array}$ & Kamar-1 & Kamar-2 & Kmr-1 & Kmr-2 \\
\hline---- & ---- & $\begin{array}{c}\text { Sistem } \\
\text { Aktif } \\
\text { Kamar 1 }\end{array}$ & $\begin{array}{c}\text { Sistem } \\
\text { Aktif } \\
\text { Kamar 1 }\end{array}$ & ---- & ---- \\
\hline 1 & 1 & $\begin{array}{c}\text { Indra } \\
\text { Ada } \\
\text { Tamu }\end{array}$ & $\begin{array}{c}--------- \\
\text { On }\end{array}$ & ---- \\
\hline 2 & 1 & --------- & $\begin{array}{c}\text { Miftah } \\
\text { Ada } \\
\text { Tamu }\end{array}$ & ---- & On \\
\hline
\end{tabular}

Kondisi awal ketika sistem aktif sebelum mendapat masukkan dari keypad tamu tampilan LCD pada penghuni adalah "Sistem Aktif Kamar 1". Ketika dimasukkan nomer kamar dan nomer nama penghuni sesuai daftar. Misalnya no. kamar 1 dan nama nomer 1. LCD pada sisi penghuni adalah " INDRA ADA TAMU" dan bel dikamar-1 berbunyi/On. Respon dari tabel 5 untuk no. kamar 1 dan nama no. 1 diperlihatkan pada tabel 6.
Tabel 6. Hasil Pengujian Respon pada Tamu

\begin{tabular}{|c|c|c|c|}
\hline \multicolumn{2}{|c|}{$\begin{array}{l}\text { Push Button } \\
\text { PENGHUNI }\end{array}$} & \multirow{2}{*}{$\begin{array}{c}\text { Respon } \\
\text { Otomatis }\end{array}$} & \multirow[t]{2}{*}{ LCD TAMU } \\
\hline Kmr-1 & Kmr-2 & & \\
\hline Ada /Biru & ---- & ----------- & Mohon Tunggu Sebentar \\
\hline $\begin{array}{l}\text { Tiadak } \\
\text { Ada } \\
\text { /Merah }\end{array}$ & ---- & On & $\begin{array}{c}\text { Maaf Yang Dicari } \\
\text { Tidak Ada }\end{array}$ \\
\hline
\end{tabular}

Jika push button "Ada" (biru) ditekan, mikrokontroller pada penghuni mengirimkan pesan ke pada tamu dan LCD muncul "Mohon Tunggu Sebenter". Push button "Tidak ada" (merah) ditekan ataupun tidak secara otomatis dalam 3 menit mikrokontroller pada penghuni mengirimkan pesan pada tamu "Maaf Yang Dicari Tidak Ada". Hasil pengujian waktu tamu menerima balasan penghuni tidak ada sebagai berikut:

Tabel 7. Hasil Pengujian Tamu Menerima Balasan

\begin{tabular}{|c|c|c|}
\hline \multirow{2}{*}{ Kamar } & $\begin{array}{c}\text { Nama } \\
\text { Penghuni }\end{array}$ & $\begin{array}{c}\text { Waktu tamu menerima } \\
\text { balasan penghuni tidak ada }\end{array}$ \\
\hline \multirow{2}{*}{1} & INDRA & 18,87 detik \\
\cline { 2 - 3 } & KULAFA & 18,71 detik \\
\hline \multirow{2}{*}{2} & MIFTAH & 18,67 detik \\
\cline { 2 - 3 } & ICH_ONE & 18,67 detik \\
\hline
\end{tabular}

\subsection{Pengujian Kecepatan Pengiriman SMS}

Hasil waktu pengujian kecepatan pengiriman SMS pada jam tamu berkunjung, sebagai berikut:

Tabel 8. Hasil Pengujian menggunakan IM3

\begin{tabular}{|c|c|c|c|}
\hline $\begin{array}{c}\text { Kartu } \\
\text { Tujuan }\end{array}$ & $\begin{array}{c}\text { Test } \mathbf{1} \\
\mathbf{1 6 . 0 0} \text { WIB }\end{array}$ & $\begin{array}{c}\text { Test } \mathbf{2} \\
\mathbf{1 8 . 2 0} \text { WIB }\end{array}$ & $\begin{array}{c}\text { Test } 3 \\
\mathbf{2 0 . 0 0} \text { WIB }\end{array}$ \\
\hline Telkom & 8.35 detik & 7.59 detik & 9.59 detik \\
\hline IM3 & 7.15 detik & 6.56 detik & 7.26 detik \\
\hline XL & 10.23 detik & 9.50 detik & 10.96 detik \\
\hline Starone & 24.40 detik & 19.06 detik & 25.80 detik \\
\hline
\end{tabular}

Tabel 9. Hasil Pengujian menggunakan Tekomsel

\begin{tabular}{|c|c|c|c|}
\hline $\begin{array}{c}\text { Kartu } \\
\text { Tujuan }\end{array}$ & $\begin{array}{c}\text { Test 1 } \\
\mathbf{1 6 . 0 0} \text { WIB }\end{array}$ & $\begin{array}{c}\text { Test 2 } \\
\mathbf{1 8 . 2 0} \text { WIB }\end{array}$ & $\begin{array}{c}\text { Test 3 } \\
\mathbf{2 0 . 0 0} \text { WIB }\end{array}$ \\
\hline Telkom & 7.69 detik & 7.73 detik & 9.12 detik \\
\hline IM3 & 7.83 detik & 6.80 detik & 7.33 detik \\
\hline XL & 10.74 detik & 10.68 detik & 12.36 detik \\
\hline Starone & 27.97 detik & 20.46 detik & 21.60 detik \\
\hline
\end{tabular}


Tabel 10. Hasil Pengujian menggunakan XL

\begin{tabular}{|c|c|c|c|}
\hline $\begin{array}{c}\text { Kartu } \\
\text { Tujuan }\end{array}$ & $\begin{array}{c}\text { Test 1 } \\
\mathbf{1 6 . 0 0} \\
\text { WIB }\end{array}$ & $\begin{array}{c}\text { Test 2 } \\
\mathbf{1 8 . 2 0} \\
\text { WIB }\end{array}$ & $\begin{array}{c}\text { Test 3 } \\
\mathbf{2 0 . 0 0} \\
\text { WIB }\end{array}$ \\
\hline Telkom & 9.41 detik & 7.57 detik & 10.59detik \\
\hline IM3 & 6.61 detik & 6.48 detik & 7.61 detik \\
\hline XL & 9.82 detik & 8.12 detik & 9.95 detik \\
\hline Starone & $\begin{array}{c}25.80 \\
\text { detik }\end{array}$ & $\begin{array}{c}20.31 \\
\text { detik }\end{array}$ & $\begin{array}{c}21.21 \\
\text { detik }\end{array}$ \\
\hline
\end{tabular}

Karena hasil kecepatan pengiriman SMS menggunakan kartu IM3 paling cepat dari beberapa operator seluler lain, maka untuk pengujian tamu menghubungi tiap penghuni dipilih menggunakan kartu IM3. Seperti diperlihatkan pada tabel berikut.

Tabel 11. Hasil Pengujian Kecepatan Pengiriman SMS Tiap Penghuni

\begin{tabular}{|c|c|c|c|}
\hline \multirow{2}{*}{ Kamar } & Nama & $\begin{array}{c}\text { Test 1 } \\
\mathbf{1 6 . 0 0} \text { WIB }\end{array}$ & $\begin{array}{c}\text { Test } 2 \\
\mathbf{1 8 . 2 0} \text { WIB }\end{array}$ \\
\hline \multirow{2}{*}{1} & INDRA & 8.28 detik & 6.73 detik \\
\cline { 2 - 4 } & KULAFA & 7.15 detik & 6.56 detik \\
\hline \multirow{2}{*}{2} & MIFTAH & 7.32 detik & 6.45 detik \\
\cline { 2 - 4 } & ICH_ONE & 7.15 detik & 6.37 detik \\
\hline
\end{tabular}

\subsection{Analisa}

Dari hasil pengujian sub-sistem maupun integrasi sistem dapat dianalisis sebagai berikut:

- Berdasarkan hasil pengujian protokol komunikasi (PDU) handphone Siemens M35 diketahui bahwa untuk bisa berkomunikasi dengan handphone Siemens M35 diperlukan penyesuaian protokol pada baudrate 19200 bps.

- Hasil Kecepatan pengiriman SMS pada jam tamu berkunjung pukul 16.00 hingga 20.00 WIB yang tercepat dari beberapa Operator Seluler adalah Indosat IM3 (Tabel 8,9 dan 10).

- Data masukkan dari keypad pada bagian tamu berupa nama dan nomor HP tamu berhasil diproses oleh sistem minimum pada sisi tamu dan dikirimkan dengan baik pada $\mathrm{Hp}$ penghuni/user yang diluar rumah (Tabel 4).

- Sistem minimum pada bagian penghuni berhasil memberikan respon otomatis ketika penghuni tidak ada dengan waktu rata-rata 18,7 detik.

- Toleransi waktu (delay) yang diberikan melalui pemrograman apabila tidak ada respon dari penghuni adalah 3 menit.

\section{KESIMPULAN}

Dari hasil implementasi sistem yang telah dilakukan, dapat ditarik kesimpulan bahwa :
1. Kecepatan pengiriman SMS nama dan nomor HP tamu tergantung pada kondisi kepadatan trafik SMS center, karena pada waktu pengambilan data tamu berkunjung trafik SMS center cukup padat dan banyak pelanggan yang menggunakannya.

2. Nomer kamar dan nomer nama penghuni yang terdapat pada daftar kamar dan penghuni saja yang dapat dihubungi oleh tamu.

3. Seluruh sistem minimum baik pada bagian tamu maupun penghuni pada sistem penerima tamu dengan komunikasi alternatif secara nirkabel yang telah dibuat dapat memberikan kemudahan bagi pengguna (pemilik rumah maupun tamu) untuk melakukan komunikasi secara langsung dan jarak jauh.

4. Sistem penerima tamu yang telah dibuat dapat mengetahui kedatangan tamu dan memastikan ada tidaknya penghuni didalam rumah serta tamu dapat berkomunikasi secara nirkabel menggunakan Handphone yang diawali koneksinya oleh piranti mikrokontroler.

\section{DAFTAR PUSTAKA}

[1] Iman Ma'rifatul, "Rancang Bangun Sistem Otomatisasi Pintu Garasi Berbasis Mikrokontroller Dengan SMS - Pengontrolan Pintu Otomatis Menggunakan Atmega8535-", PENS/ITS, 2005

[2] Purnomo, Panduan Praktis Pemrograman AVR Microcontroller AT90S2313. Andi, Yogyakarta 2005.

[3] Siswoyo Rudi, "Rancang Bangun Sistem Otomatisasi Pintu Garasi Berbasis Mikrokontroller Dengan SMS - Pembuatan Software SMS- ", PENS/ITS, 2005

[4] Saputro Bismo, Santoso Eko, "Rancang Bangun Alat Pendeteksi Kedatangan Tamu Dengan Sistem Dial Otomatis Kenomor Telepon Tertentu". PENS/ITS, 2003

[5] Wardana Lingga, "Belajar Sendiri Mikrokontroller AVR Seri Atmega85835 Simulasi, Hadware, dan Aplikasi". Andi, Yogyakarta 2006

[6] Yeralan Sencer, Ahluwalia Ashithosh, Programming and Interfacing the 8051 Microcontroller, Addison-Publising Company, New York, 1995 